\title{
Negative Evidence in Iranian Children: How do Iranian Parents Correct Their Children's Errors?
}

\author{
Parviz Birjandi \\ Faculty of Foreign Languages and Literature, Islamic Azad University (Science and Research Branch), Tehran, Iran \\ Email: pbirjandi@yahoo.com \\ Atefeh Nasrolahi \\ Faculty of Foreign Languages and Literature, Islamic Azad University (Science and Research Branch), Tehran, Iran \\ Email: nasrollahi.atefeh@yahoo.com
}

\begin{abstract}
The most acceptable assumption in the past in child language acquisition research was that parents do not correct the grammatical errors of their children. However, today scholars believe that parents use different kind of corrective responses. To address these issues, this study focuses on Iranian parents' correction of children's errors. The samples of the present study were 62 educated parents in the city of Babol who had children between the ages of 2 to 5 . These parents were supposed to answer three main questions regarding children's error correction. 1) How do you usually correct your child errors? 2) What kind of errors do you mostly correct? 3) How do you understand your child recognized the correction? The results of the study revealed that although parents claimed that they are used to children's errors and even enjoy errors their children make, about $61 \%$ of parents corrected children's errors. The results also revealed that parents correct children's grammatical errors more than other kind of errors.
\end{abstract}

Index Terms—negative evidence, positive input, feedback

\section{INTRODUCTION}

We do not learn language in vacuum, we learn language in conversation. Children learn conventional forms and functions in conversations with others. They learn how to express their intentions and also how to interpret the intentions of others. Adults' speech to children act as the prerequisite environmental factor to trigger their innate language acquisition device (LAD).Some researchers believe that the speech children receive around them is too poor to learn from, so they have claimed that children have an innate language acquisition device (LAD).

There are different views about the input the child receives. Nativists believe that the only input resource available to the child is the linguistic information. They also claimed that negative evidence and positive input, will be identical from the child's point of view (Saxton, 1997). Saxton (1997, p.147) defined positive input and negative evidence as the following:

"Positive input is defined as any input utterance which models grammatical structures, excluding all instances of negative evidence and negative evidence supplies the correct adult model directly following a child error, while positive input supplies the correct form in all other discourse contexts."

$\mathrm{He}$ further mentioned that "Negative evidence occurs directly contingent on a child error, (syntactic or morphosyntactic), and is characterized by an immediate contrast between the child error and a correct alternative to the error, as supplied by the child's interlocutor" (p. 145).

As the definition shows a child can not correct his errors based on the positive inputs he is always encountered. He should also be exposed on some kind of negative evidence to correct his errors. In fact negative evidence according to Saxton (1997) is a prerequisite for child to get rid of errors. Negative evidence and positive input are the same in terms of the linguistic information they convey to the child, however they differ only in the context they are used, negative evidence only is immediately used after the child made an error.

\section{REVIEW OF RELATED LITERATURE}

There is not a consensus on the role of negative evidence in language acquisition. Nativists completely reject negative evidence argument. They believe no one correct child's errors (Flevaris, 2011). They claim children can filter out the ungrammatical statements from grammatical statements based on their innate capacity and the frequency of these statements. Based on their innate knowledge children can guess possible grammatical structures. Furthermore grammatical structures are heard more frequently in the environment and that's the reason why children could easily correct their erroneous structures (Saxton et al. 2005). Morgan and Travis (1989 as cited in Morgan et al., 1995) argue that corrective responses do not occur with sufficient frequency or regularity in the input to be considered essential for learning. Very often, correction may not help at all. On the other hand non-nativist proponents believe negative input 
has a crucial role in shaping the grammaticality of child's language. Chouinrad and Clark (2003) claim negative evidence is sufficient for children to correct their errors. Others like Saxton et al. (2005) believe on the existence of inner mechanism for language learning but do not completely reject the role of corrective like Nativist. Saxton (1997) provides evidence that the child's immediate responses to negative input are often consistent with its corrective function. Saxton (1997, p.146) provides the following examples:

1. Child: That policeman falled all the way down to the tiger.

Adult: He fell down.

Child: Yes, he did. He fell down 'cause he likes that tiger.

2. Child: It's even gooder than anything. (repeated 4 times)

Adult: Yes, it's better.

Child: Better, yeah.

He reaches the conclusion that "naturalistic data reveal that children sometimes shift from erroneous to correct versions of particular structures following the intervention of negative evidence" (p.147).

Saxton et al. (2005) believe that negative evidence is necessary for language learning and this is not at all in contrast to innate capacity. They believe that a rich input does not mean that there is no innate capacity for language learning:

"Logically, both could co-exist. Essentially, nativist theorists pose the question "what would the child's endowment for language look like if negative input were not available?" In so doing, one is more likely to discover the full nature and extent of innate structure in language acquisition." (P. 667).

\section{A. Parental Error Correction}

Children are exposed to many incorrect forms. When adults speak they usually change their minds, make slips of the tongue and so on. Parents also make grammatical errors when they speak. However all children grow up knowing the language perfectly. How is it possible? Do children retreat their grammatical errors on the basis of innate capacity or from the feedback they receive from adults?

Under the influence of Chomskyan paradigm scholars believe that parents do not usually correct their children's grammatical errors they usually correct the content of their children's speech rather than their grammatical errors. Grammatical errors are only rarely corrected.

Brown \& Hanlon (1970 as cited in Marcus, 1993) found that children's grammatical errors were not corrected and they were supposed to make distinction between what is grammatical and what is not grammatical based on their LAD. In fact their findings provide empirical support for Chomsky's argument from the poverty of the stimulus. If children do not receive any support from the linguistic environment then they should definitely rely on their inner capacity.

Saxton et al. (2005) mentioned that parental correction encompasses a form of negative input that is the information about which statements are ungrammatical, such as corrections or other forms of feedback from a parent that tell the child about the ungrammaticality of his utterance. Children are bombarded with a special kind of speech that is simple, fluent, grammatically correct, and context bound. Children do not learn in isolation. Many parents help their children in conveying correct form of their intended meaning. Parents help their children to make full sentences, help them paraphrase or repeat the correct form of their utterances (Pinker, 1984). Although child directed speech can help children to extract the correct form of language, they differ from negative evidence (Snow, 1997).

Negative input can control language acquisition and help children to get rid of errors they make in the process of language acquisition. A well example of this kind is stated in Marcus, et al. (1992 as cited in Saxton et al. 2005) where children make errors with past tense forms of irregular verbs. The child grammar at that time permits both *breaked and broke, while adults' grammar only permit broke. In some phases of language acquisition as Saxton et al. (2005) claimed child's grammar permits two forms where the adult grammar allows only one. In this case negative inputs help child to understand which structures are obligatory.

\section{B. Prerequisites of Adults' Correction of Children's Errors}

Marcus (1993) mentioned that there are two ways that a child can understand his sentence is ungrammatical: external clues from others or internal mechanism. Parents can provide children with an explicit rejection of ungrammatical sentence that is explicit negative evidence or the child should be equipped with a mechanism which avoid ungrammatical sentences.

Negative evidence according to Saxton et al. (2005) creates a unique context for the child to understand the contrast between his utterance and those produced by adults. In order to make this contrast, the child needs two prerequisites. First, the child understands the form produced by the adult is grammatical and second, he should understand that his own utterance is ungrammatical.

\section{Different Kinds of Negative Evidence}

Marcus (1993) named three kinds of negative evidence: complete feedback, partial feedback and noisy feedback. Complete feedback is used only for ungrammatical sentences; it is not used for correct sentences. Partial feedback is followed by some ungrammatical sentences, but never is used after correct sentences. Noisy feedback "is a corrective signal provided after some errors and after some correct sentences, but in different proportions" (P. 59). 
Marcus (1993) claimed that the only available feedback children receive is noisy feedback, which means children receive feedback following both grammatical and ungrammatical speech. Children almost certainly do not receive complete feedback or even partial feedback. "Nobody, though, has ever provided any evidence that children receive complete feedback; every reply type studied in the discourse studies is not provided for all ungrammatical sentences, and is provided for some grammatical sentences" (P. 60). Noisy feedback decreases with age. Hirsh-Pasek et al. (1984) mentioned "sensitivity to well-formedness is only apparent among [parents of] 2-year-olds. The same pattern of results failed to emerge at other ages" (p. 86).

\section{Why do Children Rely on Adults Conventional Forms as the Correct Form?}

When the child makes an error and adults correct it the child is exposed to two forms for the same meaning (Chouinard \& Clark, 2003). Base on the Principle of Contrast, the same meaning cannot be carried by more than one form (Clark, 1993). So the child must choose only one form and since adults are the more expert speakers, children prefer the form produced by adults (Clark \& Bernicot, 2008).

Sameness of meaning is very important. If the meaning proposed by children is not interpreted correctly by adults, the child tries verbally and non-verbally to inform the adults of her intended meaning (Chouinard \& Clark, 2003). But when the child is sure that the two forms convey the same meaning, he would prefer adults' form. Saxton (1997) mentioned that if the corrective information is used in contingent to child erroneous utterance show the child the contrast between his erroneous utterance and the correct alternative produced by adult. Once children become aware that two forms convey the same meaning, they will adopt the adult conventional form instead of their own erroneous expression. According to Chouinard and Clark (2003) adult correction could have different meaning for children:

a) they made an error;

b) the place of that error, and

c) the correct form to be used instead.

In fact by comparison of their own utterance and adults form children will recognize the place of the error and "identify the conventional form that they should have used for that meaning" (p. 643). Saxton (1997) mentioned that "despite what other differences may exist between child and adult utterances, [children] adopt the form favoured by the adult in place of their own version"(p. 157).

Chouinard and Clark (2003) stated that children give evidence of attending to the adult reformulations they hear by repeating the corrected forms, by acknowledge them with responses like yeah or uh-huh. The important point according to Clark and Bernicot (2008) is that even if children don't use adults' conventional forms they would easily store adults' conventional forms in their memory so that after awhile they have the required potential to correct errors. Marchman and Bates (1994) believes that children have some threshold level of exposure before they fully adopt an adult form to replace their own form.

\section{RESEARCH QUESTIONS}

The nativist assumption in theories of child language acquisition is that parents do not correct the grammatical errors of their children. That is, the child is said to receive no negative evidence (Pinker, 1989). They believe there is no difference between positive input and negative evidence. They both shape the linguistic input the child is supposed to receive from environment. However according to Saxton (1997) the proponents of "Contrast Theory" believe that not only children can differentiate between positive input and negative evidence but also children react to them differently. Negative evidence seems to be more effective than positive input, because it encourages the child to use adults' correct forms.

To our knowledge, there seem to be few researches on parents' view in correcting their children erroneous utterances. So the researchers tried to check how Iranian parents mostly correct their children. The focus in the current article is different kinds of parental correcting on Iranian children acquiring Persian as their first language. Participants were supposed to answer the following questions:

1) How do you usually correct your child errors?

2) What kind of errors do you mostly correct?

3) How do you understand that your child accepted the correction?

\section{METHOD}

\section{A. Participants}

The samples of the present study were 62 educated parents in the city of Babol who had children between the ages of 2 to 4 . They were aged between 22-45 years old. Twenty one of them were having their first child, thirty six of them were having their second child, and five had their third child. They were supposed to answer to the above mentioned questions.

\section{B. Design}


It should be noted that this study is a descriptive one. According to Best and Kahn (2006) argue that descriptive research seek to find answers to "analysis of past events or the already existing conditions" (p. 133). It describes and interprets what exist. Because the researchers had no control over what has already happened to the subjects of the present study an Ex-Post Facto design was needed.

\section{Data AnAlysis}

In order to test the hypothesis, first parents answer the three above mentioned questions. Then, based on their answers the researchers divided them into ten separate elements to be studied separately. Each of these subcategories is discussed bellow.

In order to answer the first question on "How do you usually correct your child errors?" and based on the participants' answers the following answers were elicited.

As the following table shows a small part of participants stated that they correct their children's errors directly and about 69 percent of them rejected direct correction.

TABLE 1.

DO U CORRECT YOUR CHILD'S ERROR DIRECTLY

\begin{tabular}{|ll|l|l|l|l|}
\hline & & Frequency & Percent & Valid Percent & Cumulative Percent \\
\hline Valid & yes & 19 & 30.6 & 30.6 & 30.6 \\
& no & 43 & 69.4 & 69.4 & 100.0 \\
& Total & 62 & 100.0 & 100.0 & \\
\hline
\end{tabular}

As the table 2 shows about 38 percent of participants neglected children's errors and about 61 percent of them corrected their children's errors.

TABLE 2.

DO NOT PAY ATTENTION TO ERRORS

\begin{tabular}{|ll|l|l|l|l|}
\hline & Frequency & Percent & Valid Percent & Cumulative Percent \\
\hline Valid & yes & 24 & 38.7 & 38.7 & 38.7 \\
& 38 & 61.3 & 61.3 & 100.0 \\
& no & 100.0 & 100.0 & \\
& Total & 62 & &
\end{tabular}

As the table 3 shows 66 percent of the participants use some kinds of recast to correct their children's errors, while 33 percent of them used other kinds of correction such as expansion.

TABLE 3.

REPEAT THEIR SENTENCE WITH CORRECTION

\begin{tabular}{|c|c|c|c|c|c|}
\hline & & Frequency & Percent & Valid Percent & Cumulative Percent \\
\hline \multirow[t]{3}{*}{ Valid } & yes & 41 & 66.1 & 66.1 & 66.1 \\
\hline & no & 21 & 33.9 & 33.9 & 100.0 \\
\hline & Total & 62 & 100.0 & 100.0 & \\
\hline
\end{tabular}

Most of the parents in this study as shown in the following table believe that context is so rich that they don't need ask children for clarifications of their intended meaning.

TABLE 4. DIRECTLY ASK CHILD TO CLARIFY WHAT THEY MEAN

\begin{tabular}{|ll|l|l|l|l|}
\hline \multicolumn{5}{|c|}{ DIRECTLY ASK CHILD TO CLARIFY WHAT THEY MEAN } \\
\hline & Frequency & Percent & Valid Percent & Cumulative Percent \\
\hline Valid & yes & 25 & 40.3 & 40.3 & 40.3 \\
& 37 & 59.7 & 59.7 & 100.0 \\
& no & 100.0 & 100.0 & \\
& Total & 62 & & & \\
\hline
\end{tabular}

In order to answer the second question on "What kind of errors do you mostly correct?" Based on the elicited answers the researchers found that parents in most cases correct grammatical and phonological errors of children as they correct pragmatics errors. The following tables confirm these findings. 
TABLE 5.

MOSTLY CORRECT THEIR PHONOLOGICAL ERRORS

\begin{tabular}{|ll|l|l|l|l|}
\hline \multicolumn{5}{|c|}{ MOSTLY CORRECT THEIR PHONOLOGICAL ERRORS } \\
\hline Valid & Frequency & Percent & Valid Percent & Cumulative Percent \\
\cline { 2 - 5 } & 40 & 64.5 & 64.5 & 64.5 \\
& no & 22 & 35.5 & 35.5 & 100.0 \\
& Total & 62 & 100.0 & 100.0 & \\
\hline
\end{tabular}

TABLE 6.

MOSTLY CORRECT THEIR GRAMMATICAL ERRORS

\begin{tabular}{|ll|l|l|l|l|}
\hline & Frequency & Percent & Valid Percent & Cumulative Percent \\
\hline Valid & yes & 43 & 69.4 & 69.4 & 69.4 \\
& 19 & 30.6 & 30.6 & 100.0 \\
& no & 100.0 & 100.0 & \\
& Total & 62 & & &
\end{tabular}

TABLE 7.

MOSTLY CORRECT THEIR PRAGMATICS ERROR

\begin{tabular}{|ll|l|l|l|l|}
\hline & Frequency & Percent & Valid Percent & Cumulative Percent \\
\hline Valid & yes & 18 & 29.0 & 29.0 & 29.0 \\
& no & 44 & 71.0 & 71.0 & 100.0 \\
& Total & 62 & 100.0 & 100.0 & \\
\hline
\end{tabular}

Participants in answering to the last question "How do you understand that your child accepted the correction?" revealed some interesting results. Although most articles studied by the researchers found that children usually used head nods to inform adults that they understood the problem, this was somehow rare in the Iranian context. Most children under study only stop for short moments after correction and surprisingly this has not been mentioned in the previous articles done out of Iran. Children also used lots of side-sequence answers such as uh-hu and ok which they pronounce "khob" or "kha" in Persian in reaction to parents' correction.

TABLE 8.

ANSWERS LIKE YES/NO, UH-HU

\begin{tabular}{|c|c|c|c|c|c|}
\hline & & Frequency & Percent & Valid Percent & Cumulative Percent \\
\hline \multirow[t]{3}{*}{ Valid } & yes & 42 & 67.7 & 67.7 & 67.7 \\
\hline & no & 20 & 32.3 & 32.3 & 100.0 \\
\hline & Total & 62 & 100.0 & 100.0 & \\
\hline
\end{tabular}

TABLE 9.

HEAD NODS

\begin{tabular}{|ll|l|l|l|l|}
\hline & Frequency & Percent & Valid Percent & Cumulative Percent \\
\hline Valid & yes & 12 & 19.4 & 19.4 & 19.4 \\
& 50 & 80.6 & 80.6 & 100.0 \\
& no & 100.0 & 100.0 & \\
\hline
\end{tabular}

TABLE 10.

PAUSING AFTER CORRECTION

\begin{tabular}{|ll|l|l|l|l|}
\hline & Frequency & Percent & Valid Percent & Cumulative Percent \\
\hline Valid & yes & 41 & 66.1 & 66.1 & 66.1 \\
& 21 & 33.9 & 33.9 & 100.0 \\
& no & 100.0 & 100.0 & \\
\hline
\end{tabular}

\section{CONCLUSION AND LimitATIONS OF THE STUDY}

The existence and effectiveness of negative evidence seems to be a very important question in the study of language acquisition, because by rejecting negative evidence in retreating child's error one would conclude the child is relying on his innate capacity to learn the language (Marcuse, 1993). There seem to be great controversies in the effectiveness of negative evidence. Saxton et al. (2005) consider negative input as unnecessary component of language acquisition. They quoted "Corrective input might facilitate language acquisition without being in any way essential" (p. 670). Marcus (1993) argues that parents provide noisy feedback for correcting children's utterances and it is hard to believe 
children can use these noisy feedbacks to diminish their errors. He believes children seem to rely on their internal mechanisms. He concluded that "internal mechanisms are necessary to account for the unlearning of ungrammatical utterances" (p. 53). However non-nativist scholars like Chouinrad and Clark (2003) who assume that child learns language with no language-specific device view input as the primary source of all linguistic knowledge. They believe negative input has a crucial role in shaping the grammaticality of child's language. The results of their study shows that "adults reformulate erroneous child utterances often enough for learning to occur" (p. 667).

The finding of the present study shows that only $30 \%$ of Iranian parents correct their children's errors directly. The results also shows parents are sensitive to the kind of errors children make. They mostly correct syntactic and phonological problems of their children.

Studies have found that mothers retreat their children's ungrammatical statements no more than $34 \%$ of the time (Hirsh-Pasek, et al., 1984; Farrar, 1992) which according to Flevaris (2011) is not enough for the removal of errors. The findings of present study reject nativist assumptions of language acquisition which completely deny the role of negative evidence. It also rejects non-nativists views that place no role for innate mechanism. As the results show Iranian parents do correct their children and their correction seem to be facilitative for language learning but this cannot deny the role of innate mechanism. As Morgan et al. (1995) suggest negative evidence cannot replace internal mechanism. The child must have some mental mechanisms that rule out the grammatical utterances produced by adults. In sum our findings support Saxton (1997) views which mentioned negative input along with positive input and internal mechanism shapes the child language:

"The discovery that negative input plays a role in the recovery from errors would not allow one to conclude that innate factors and positive input have no role to play in the retreat from overgeneralization. In fact, it would not be surprising to discover that all three factors (innate attributes, positive input and negative input) contribute in some way" (p. 159).

It is important to note limitations of the current study and its findings. First, and most significant, this study has been conducted only in one city with about 62 participants. Definitely the greater number of participants from different regions can give us a better picture of error correction in Iranian children. In addition different socioeconomic characteristics of parents can significantly relate to their perception of children's errors and their corrections. Parents who participated in this study seem to be somehow from the same socioeconomic backgrounds. Other studies should be done within different socioeconomical levels. Finally replication studies in other sociocultural contexts, could serve as important future contrasts to the present studies.

\section{REFERENCES}

[1] Best, J.W., \& Kahn, J.V. (2006). Research in Education. (10 $0^{\text {th }}$ ed.) New York: Pearson Education Inc.

[2] Chouinrad, M. M., \& Clark, E. V. (2003). Adult reformulations of child errors as negative evidence. Journal of Child Language, 30, 637-669.

[3] Clark, E. V. (1993). The lexicon in acquisition. Cambridge: CUP.

[4] Clark, E.V., \& Bernicot, J. (2008). Repetition as ratification: How parents and children place information in common ground. Journal of Child Language, 35, 349-371.

[5] Farrar, M. J. (1992). Negative evidence and grammatical morpheme acquisition. Developmental Psychology 28(1), 90-98.

[6] Flevaris, T. (2011). Nativism in Linguistics: Empirical and theoretical issues. Retrived 19 May, 2011 from www.linguistics.northwestern.edu/programs/demoz.../Flevaris.

[7] Marchman, V. A. \& Bates, E. (1994). Continuity in lexical and morphological development: A test of the critical mass hypothesis. Journal of Child Language 21, 339-366.

[8] Marcus, G. F. (1993). Negative evidence in language acquisition. Cognition, 46(1), 53-85

[9] Morgan, J. L., Bonamo, K.M. \& Travis, L. L. (1995). Negative evidence on negative evidence. Developmental Psychology, 31(2), 180-197.

[10] Pinker, S. (1984). Language learnability and language development. Cambridge, MA: Harvard University Press.

[11] Pinker, S. (1989). Learnability and cognition: the acquisition of argument structure. Cambridge, MA: MIT Press.

[12] Saxton, M. (1997). The contrast theory of negative input. Journal of Child Language 24, 139-161.

[13] Saxton, M. (2000). Negative evidence and negative feedback: immediate effects on the grammaticality of child speech. First Language 20, 221-252.

[14] Saxton, M., Backley, P., \& Gallaway, C. (2005). Negative input for grammatical errors: Effects after a lag of 12 weeks. Journal of Child Language, 32 (3), 643-672.

[15] Snow, C. E. (1997). Conversation with children. In P. Fletcher \& M. Garman (Eds.). Language acquisition: Studies in first language development (pp. 69-90). Cambridge: CUP.

Parviz Birjandi is a full professor of TEFL. He is holding an M.A. in applied linguistics from the Colorado State University and a Ph.D. in English education; minor: Research methods and statistics from the University of Colorado. He has got his B.A. from Tehran University in the 1970s. He has established TEFL in many Iranian universities in his long effective career. Many Iranian Ph.D. holders of TEFL and hundreds of M.A. holders have been his students in different Iranian universities. He is considered as "the Founder of Iranian TEFL" by many university professors and educational experts in Iran. He has published more than 40 articles in 
the area of TEFL and he is the author of English textbooks for high school and pre-university levels, used nationwide, more than 10 university textbooks and many practice textbooks.

Atefeh Nasrollahi is currently a PhD student at Islamic Azad University, Science and Research Branch, Tehran, Iran. She received her M.A. degree from Islamic Azad University, Science and Research Branch, Tehran, in 2008. She has presented some articles in different international conferences. Her primary research interests concerns different language learning strategies, second language acquisition, and first language acquisition. She is currently teaching general English courses at Islamic Azad University Amol branch. 